\title{
WIND TURBINES DESIGNED FOR EASY INSTALLATION
}

\author{
OVE T. GUDMESTAD \\ University of Stavanger, Norway
}

\begin{abstract}
The costs of installation, intervention/maintenance and decommissioning of fixed bottom, founded offshore wind turbine concepts are unreasonably high when using state of the art technology. For such wind turbine concepts, state of the art is to use jackups or crane vessels for said operations. This might not be attractive in view of the large costs of employing sufficiently sized equipment that can operate under most weather conditions. In particular, there is a concern regarding the limited availability of offshore wind turbine installation-equipment in situations where there are larger waves most of the year, as in the North Sea. The investment costs for the wind turbines are thus larger than necessary. There is thus a need for new thinking to develop safe but less costly technology and procedures for these operations. Furthermore, heavy maintenance is particularly difficult for offshore wind turbines, requiring the use of expensive offshore vessels, i.e. vessels requesting high day rates during operations. In view of this, new technical solutions are, in this paper, proposed for the installation, intervention/maintenance and decommissioning of offshore wind concepts. In particular, the use of ballast procedures combined with use of the less costly offshore service vessels to perform offshore operations safely will be investigated. Similarly, the state of art design of the wind turbines requires the use of large cranes for heavy maintenance of said equipment and it might be considered to lower the nacelle to perform such operations. These operations shall not, however, get in conflict with the requirement that the blades shall never touch the sea surface under any activity. The design is extended to floating wind turbines which can be optimized for cost saving fabrication and installation using the method described for the fixed wind turbine designs.
\end{abstract}

Keywords: wind turbine installation, offshore support vessels, telescope solutions, maintenance, floating wind turbine design.

\section{INTRODUCTION}

For bottom fixed offshore wind turbine concepts in shallow water, state of the art is to use jack-up type vessels for offshore operations. The jack-up technology is, however, vulnerable to waves, in particular during shifting location from one activity to another. It may be noted also that the spud cans would leave large footprints in softer soils. The effects of these limitations may be high downtime during installation and heavy maintenance operations. It should, in particular, be noted that the need to change location of the service vessel very often during wind farm installation and maintenance work, highlights the requirement for suitable weather windows as the jackup will have to change from fixed mode to floating mode and back to fixed mode. It would be greatly advantageous from an economic point of view if service/support vessels developed for the offshore oil and gas industry or specialized service vessels that stay on location on dynamic positioning, could be used for these operations.

For bottom fixed offshore wind turbine concepts in deeper waters, state of the art is to use crane vessels for offshore installation and maintenance operations; however, the use of these vessels might not be attractive in view of the costs of employing sufficiently sized vessels that can operate under a variety of weather conditions. It should be noted that smaller barge type crane vessels might have movement characteristics (resonance between waves and the heave, pitch and roll periods of these vessels) that will make such operations difficult or impossible during long periods of the year, in particular in North Sea wave climate conditions. It would also be greatly advantageous for these wind turbines if offshore service vessels developed for the offshore oil and gas industry could be used for offshore operations. 
A recent study of the details of 87 wind farms installed between 2000-2017 is presented by Lacal-Arántegui et al. [1]. For discussions of the State of Art technology, see [2]-[6]. More details of actual installation of offshore wind turbines is disused in Gudmestad et al. [7]. Reference is also given to Lloyds Register [8].

\section{THE WEATHER CONDITIONS NEEDED FOR INSTALLATION USING JACKUPS}

Several purpose-built jackups have been commissioned and have been involved in wind farm construction work. There are, however, strong limitations when it comes to the availability and operability of jackups. Start-up on installation work on the German Alfa Ventus wind farm off Borkum was, for example, delayed during the winter of 2008/2009 as "high swells and strong winds initially delayed the beginning of construction". In order to estimate the weather downtime for jackup activities, it is necessary to distinguish between estimated seasonal downtime and the actual weather dependent downtime. For the estimated downtime, the following information is needed:

- First the wave climate (seasonal) for the area must be known. This includes statistics of wave heights and wave periods.

- The estimated downtime is found by assessing the criteria for jackup movements, which depends upon the heave and pitch response of the jackup to the waves. The natural period of the floating jackup in heave and pitch should be as high as possible for minimizing the number of sea states where resonances could occur during its fixation at the offshore location. It must be recognized that the weather windows must include time necessary to leave location, to transfer to new location (even just some hundred meters away) and the time to secure the jackup on the new location. In case of jackups having longer natural periods, however, long swells might be of concern [9].

- Furthermore, the wind conditions where work can be undertaken will limit the availability; statistical data are necessary.

The actual downtime will of course depend on the actual weather [9]:

- Should the required weather window for the movement be less than the time of reliable weather forecasts (normally estimated to 72 hours), the jackup could wait for transfer until a favourable weather forecast.

- A Field Tow corresponds to the condition where a Jackup Unit is afloat on its own hull with its legs raised, and is moved a relatively short distance to another location. For a short move, the ability to predict the condition of the weather and sea state is relatively good. Therefore, steps to prepare the Unit for Field Tow are not as stringent as for a longer tow. Most Classification Societies define a "Field Tow" as a Tow that does not take longer than 12 hours, and must satisfy certain requirements with regards to motion criteria. It should be noted that Field Tows would be very frequent in case of installation work in a wind farm area.

The Norwegian company Norwind was involved in the installation of jackets support structures for wind towers at the Alpha Ventus wind farm project in Germany. They decided to use large crane vessel Thialf for the jacket installation and a smaller jackup for the pile driving, see [10]. The tendency to use heavier and more expensive equipment for installation works in harsher environments may not work well in the future as the economy in wind energy is not necessary as abundant as in the oil and gas industry. Huge investments in specialized equipment may not be justified, however, unless contracts are secured to ensure 
payback of the invested funds. For new technical solutions available, see, for example, JDN Group's very large jackup [11] or Van Oord's solution [12].

\section{NEW DESIGN SOLUTIONS PROPOSED}

New designs are here proposed for offshore fixed wind turbine design, potentially reducing installation costs considerably. The key is to assemble the wind turbine completely at the quayside or in a dry dock for tow to the location and easy installation at the site.

\subsection{Telescopic design}

The main merits of the concept lie in bringing the nacelle towards the sea level to ensure stability during tow, whereby the ballast requirements in the foundation structure will be reduced. The concept is shown in Figs 1 and 2. The key idea comprises a telescopic tower and blades that are turned from vertical to horizontal during tow to site. The foundation could be a jacket type structure or any type of floating structure. We could also consider to turn the complete nacelle with blades 90 degrees; however, such a solution will require considerable re-design of existing nacelle geometries. Due to the low centre of gravity for the nacelle, the additional ballast needed during tow out to secure stability (Fig. 2), is limited.

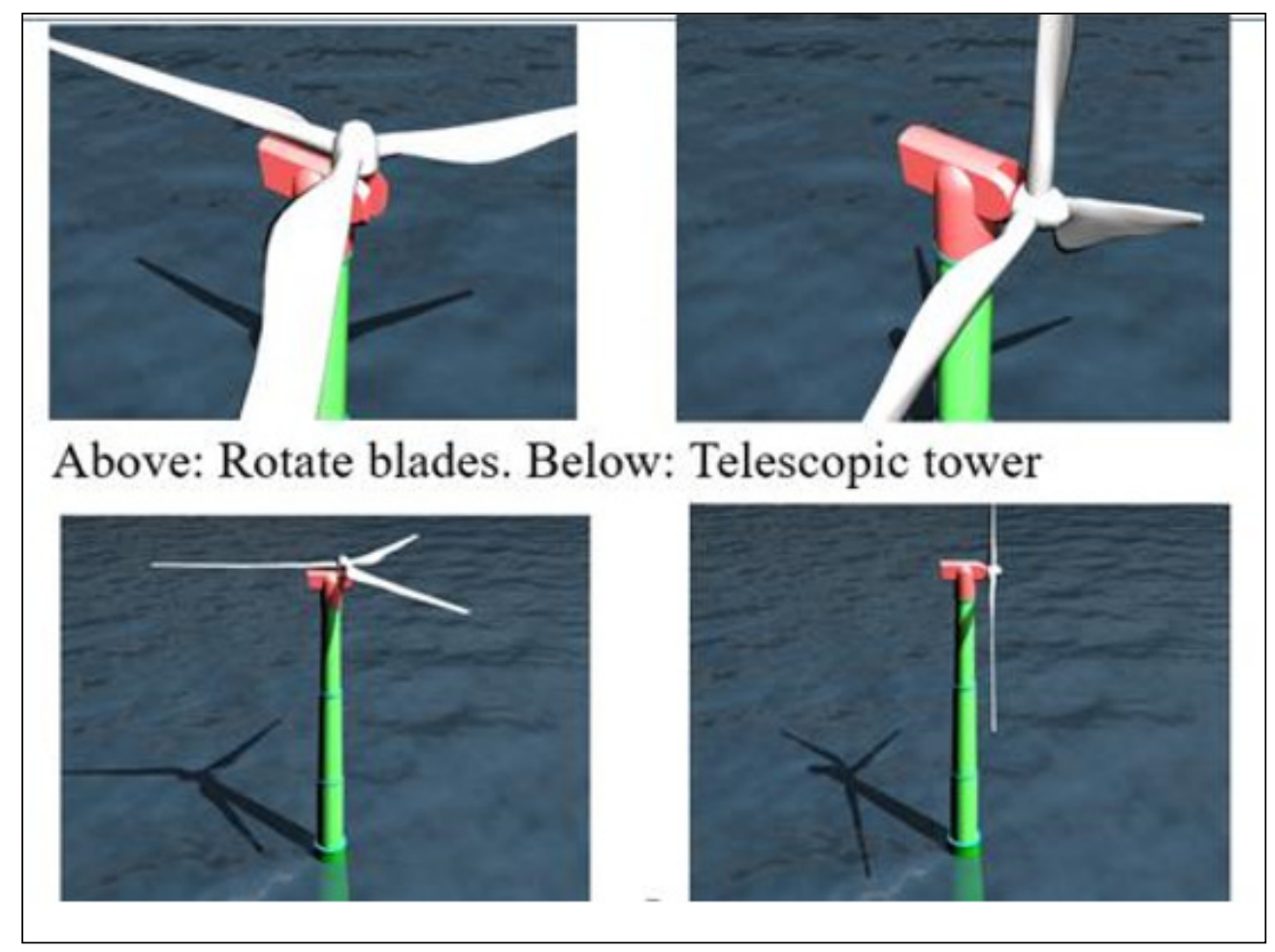

Figure 1: Wind turbine to be mounted in sheltered waters comprising a telescopic tower and blades which are turned vertical during tow to site, whereby the nacelle can be brought near to the sea level during tow to site. The blades are mounted on a hoop that is rotated with the blades while keeping the nacelle in fixed horizontal position. 

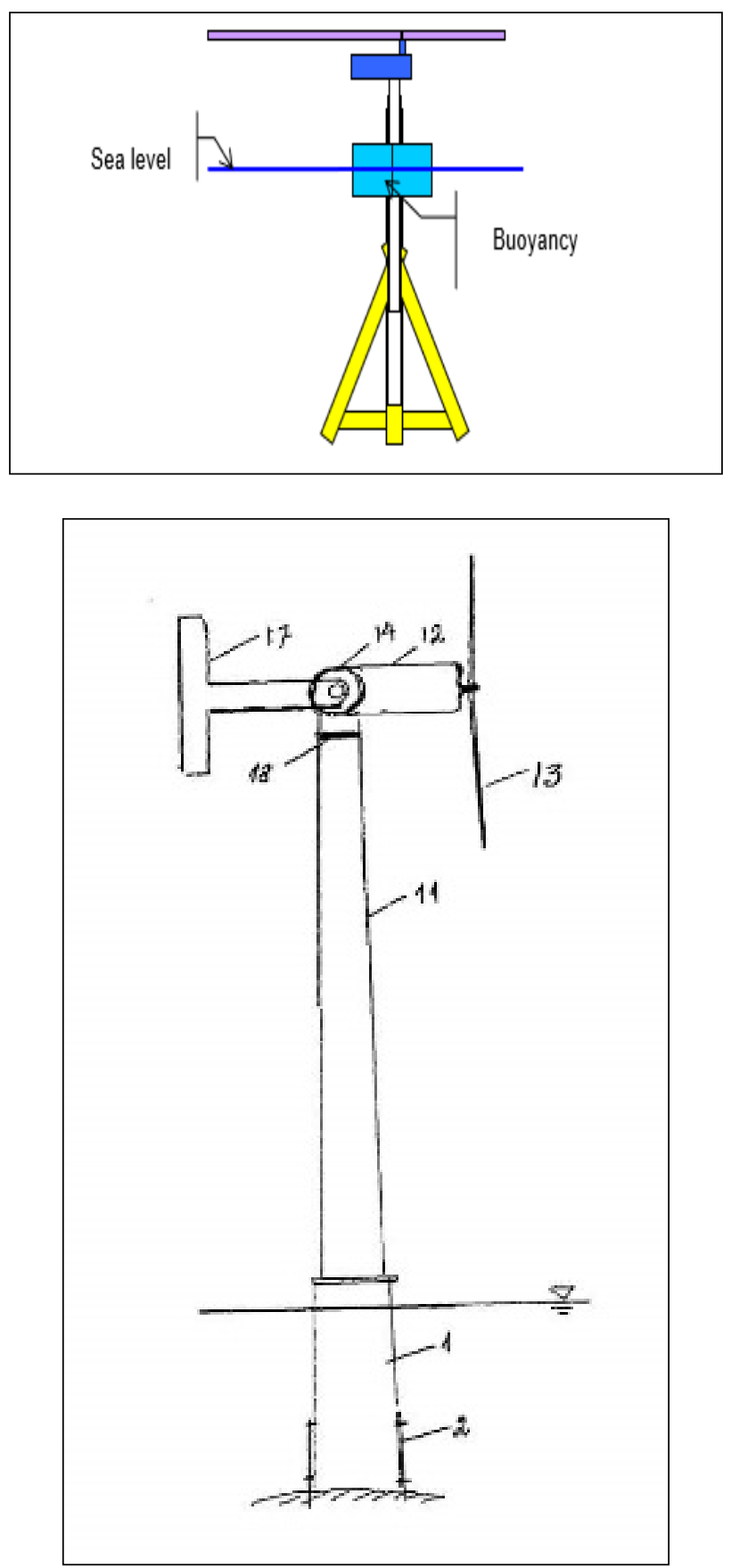

Figure 2: Top: Wind turbine (as Fig. 1) with extra buoyancy element ensuring stability during tow to site, [13]. Bottom: Wind turbine as installed on site (Figure copied from Norwegian Patent 331023). Legend: (1) foundation, (2) piles, (11) tower, (12) nacelle, (13) rotor blades, (14) joint, (17) counterweight, (18) joint. 
With respect to the concept presented above, there are needs for further work relating to the following aspects to document feasibility:

- Documentation of weather window for the alternative installation solutions

- Design of the connection between the nacelle and the blades (in cooperation with manufacturers of nacelles)

- Design of the retractable tower (telescoping design) and locking mechanisms

- Design of the foundation structure and buoyancy element(s) (if needed)

- Design of suction piles or installation of installation

- The possibility to use smaller and less costly vessels for offshore works. In particular, the possibility to use vessels with heave, pitch and roll compensators and their cranes for such work will be investigated. This might be possible as the nacelle and the blades are brought closer to the sea surface during installation and heavy maintenance.

The design presented above aims at solving or at least mitigating the drawbacks or deficiencies by providing a windmill with telescopic shaft and easy method of installation, intervention or decommissioning.

The design would be far less controversial in case of two bladed wind turbines [14] as it would not be of concern that a third blade could tip into water for a two-bladed design. The idea of turning the nacelle can thus be abandoned and the complete design is just dependent on the telescoping tower to be lifted when the wind turbine is at the offshore site.

\section{WIND TURBINE TOWED TO SITE BY OFFSHORE SUPPORT VESSEL}

A wind turbine concept which can be placed vertically on a barge and towed to site and installed by use of an offshore service vessel has been developed by the company Green Entrans AS [15]. The method (herein called "MINT") is developed for transport and installation (Fig. 3) of one-mono-tower offshore structure, termed MC-7. This offshore support structure is consisting of a mono-tower which penetrates the surface being supported by a tripod foundation. Fig. 3 (upper part) shows the structure in the transport mode. This geometry is suggested to represent a minimum support structure for the topside functions.

This transport and installation method is considered to be particularly interesting for water depths in the range from 50 to $120 \mathrm{~m}$, that is, outside the range of using mono-pile offshore structures and outside the range of the smaller installation jackups used in the wind industry for monopile foundations.

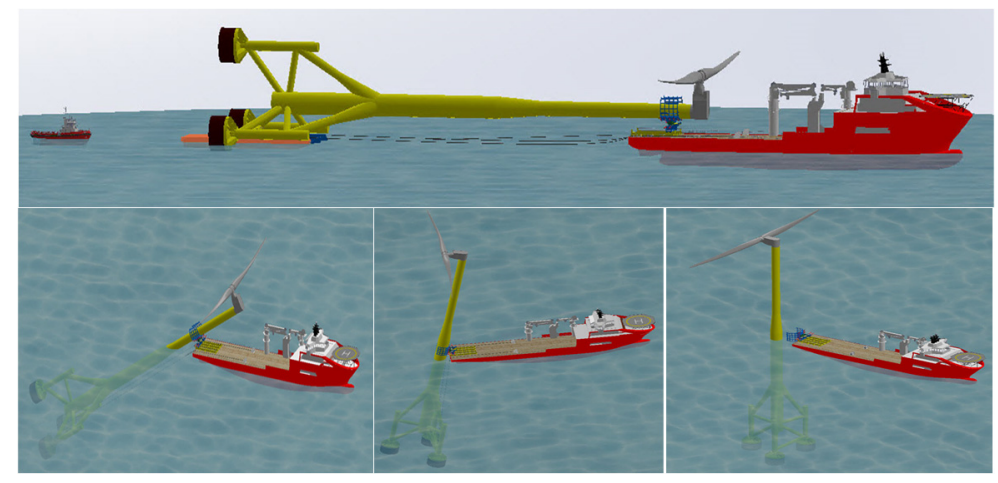

Figure 3: The MC-7 structure for water depths 50-120 m, transported and installed as a complete unit by the MINT method. 
The towing and the installation process were tested at MaREI - LiR test center in Cork, Ireland in 2018 [15]. The wave tank tests confirmed initial assessments that transport would be feasible in Hs 2.5 to $3 \mathrm{~m}$ : With adjustment of the ballasting procedure during the upending phase, the transport and installation method is found feasible:

\subsection{Transport; recommended maximum sea-state criteria}

- Hs $3 \mathrm{~m}$

- Wave periods $8-9 \mathrm{~s}$

Note: The transport survives Hs $4 \mathrm{~m}$ in $30 \mathrm{deg}$. heading. The designed Transport solution is concluded robust and ready for full scale detail engineering.

\subsection{Installation; recommended maximum criteria}

- $\quad$ Hs $2.5 \mathrm{~m}$

- Wave periods $8-9 \mathrm{~s}$

Note: The installation survives $\mathrm{Hs} 3 \mathrm{~m}$ in $30 \mathrm{deg}$. heading. The recommended transport and installation criteria are based on specific vessel and barge sizes /designs. The criteria may change when using other vessels/barges.

\subsection{Installation time}

The average time necessary for transport and installation of wind turbine by "MINT" method, beginning from start of quayside to completion of installation, is estimated as follows:

- The completed wind turbine will be skidded onto the vessel' MINT (upper part). While the vessel moves forward, the bottom part of the wind turbine (the foundation) will be transferred to the barge. The time for this operation should be one day.

- After sea fastening, one is ready for the offshore tow. The tow will be initiated when the weather conditions are within the acceptance criteria [9]. The time to wait for suitable weather criteria will always represent an uncertainty.

- Following a "go to transport", the tow could proceed at an estimated speed of 6 to 8 knots to the offshore site.

- Weather criteria are again checked at the site, sea fastening is removed and the transfer of the foundation part from the barge will start. The wind turbine will then rest on the MINT and the upending will be carried out. From removal of sea fastening to installation on the sea floor an estimated 12-18 hours will be needed.

\subsection{Safety during installation}

The measures necessary to save the equipment by accidental storm are as follows:

- The installation will commence when the tower foundation is mounted on the barge, the top of the tower is resting on the MINT and the weather acceptance criteria are met.

- Notice that the criteria given in [9] account for uncertainty in weather forecast by implementing a reduction factor, an alpha factor, such that the $3 \mathrm{~m}$ installation criterion is reduced to, typically $2.4 \mathrm{~m}$ for an operation that takes more than 3 days. 
- Should the weather deteriorate during tow to site, the spread will turn and go back to harbor and wait out the coming storm. The survival criteria will ensure safe return to safe haven.

\section{FLOATING WIND TURBINES}

The latest trend in wind engineering is to identify locations in deeper waters where floating wind turbines can be installed at minimum costs. Statoil (now Equinor) developed the Hywind concept several years ago and installed a prototype that has been in operation for several years [16]. The wind turbine is of the deep Spar type that is towed out from a relatively deep fjord fully equipped. However, such deep locations do not exist in many countries and alternative designs as, for example, the wind-float design [17], are more flexible as they can be fully equipped in a dry dock. The wind-float design has, however, the disadvantage that the floater is quite bulky to achieve the necessary stability of the wind turbine and the proper motion characteristics during the storm situations. A Spar type wind turbine that can be fully manufactured in a dry dock and towed to site through shallow ship channels (water depth in the range of 12 to $50 \mathrm{~m}$ ) would represent an optimum with respect to fabrication, installation and in place motion characteristics. The design is possible using a telescopic tower while keeping the blades in horizontal position during tow to site. At site, the telescopic tower is opened and the blades rotated to vertical position. A conceptual drawing is shown in Fig. 4. During maintenance work, the installation process could be reversed. A two-bladed version would be advantageous for installation purpose as it would not be required to tow through a deep draft fjord for tow out from a construction site.

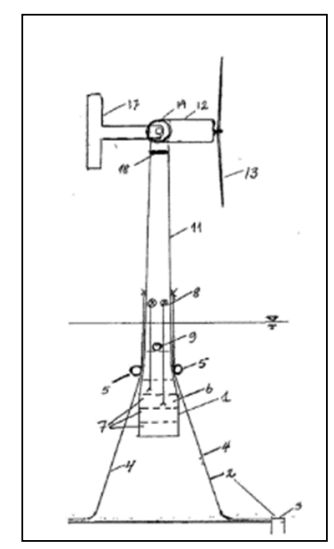

Figure 4: Floating wind turbine (installed as shown in Fig. 1) as installed on site (Figure copied from Norwegian Patent 330525). Legend: (1) flotation element, (2) anchor-system, (3) anchor, (4) anchor lines, (5) fairleads, (6) ballast system, (7) ballast tanks, (8) pumps, (9) gyro, (11) tower, (12) nacelle, (13) rotor blades, (14) joint, (17) counterweight, (18) joint.

\section{WORK REQUIRED TO DOCUMENT THE FULL FEASIBILITY OF THE SUGGESTED DESIGNS}

The proposed design will reduce the installation cost considerably for fixed wind turbines as less costly equipment will be utilized. For floating wind turbines, the proven design having the optimum response characteristics (the Spar type design) can be fabricated and installed 
without restrictions normally applicable for this design (the availability of a deep-water floatout channel).

The next step in the development is to produce a small-scale working prototype and to carry out engineering and full financial analysis to document the feasibility of the concepts [18].

\section{CONCLUSIONS}

This paper has focused on reducing costs for offshore works during installation and maintenance of offshore wind turbines placed in waters with harsh environmental conditions. The use of jackups as construction vessels for fixed wind turbines in relatively shallow water is costly, both in terms of investments in equipment and in downtime during operations. It is therefore here suggested to fabricate the wind turbines in docks or by the quayside and thereafter tow these to offshore site with the nacelle and blades placed as low as possibly to improve on the stability during the tow. It is suggested that this may be most elegantly achieved by turning the blades horizontally during tow to the offshore site. Two-bladed wind turbines will be easier to handle as one will not have to be concerned with one of the blades possibly sticking into water.

For floating wind turbines in deeper waters, it is suggested to apply the conceptual idea described for the fixed wind turbines to the Spar type wind turbines, so the optimum design at site can be fabricated in dry dock or at key side and towed out in shallow shipping channels.

For the case of fixed wind turbines in medium water depth, an alternative solution that is tested in a wave tank is documented to be feasible to transport and install at site by use of offshore service vessels.

\section{PATENTS}

The following patents are resulting from the work reported in this manuscript:

1. Windmill and method of installation, intervention or decommissioning Norwegian patent 331023 granted 2011.

https://search.patentstyret.no/Patent/20092435/?searchId=1420698\&caseIndex $=2$

2. Floating windmill and method of installation, intervention or decommissioning. Norwegian patent 330525 granted 2011.

https://search.patentstyret.no/Patent/20091484/?searchId=1400167\&caseIndex=9

\section{CONFLICT OF INTERESTS}

The author states that the patents referred to have been transferred to the Norwegian registered company Gudme Stad AS and that the author can be contacted for discussions regarding the further development of the technology.

\section{ACKNOWLEDGEMENT}

The author acknowledges the support of the University of Stavanger in developing the technology described.

\section{REFERENCES}

[1] Lacal-Arántegui, L., Yusta, J.M. \& Domínguez-Navarro, J.A., Offshore wind installation: Analysing the evidence behind improvements in installation time. Renewable and Sustainable Energy Reviews, 92, pp. 133-145, 2018. 
[2] SBM, GustoMSC, Equipment for Offshore Wind Turbine installation, 2018. www.kivi.nl/uploads/media/5644b984995fc/Offshore\%20Windturbine\%20Installatie \%3B\%20hoe\%20hoog\%20kun\%20je\%20gaan\%20-\%20ir.\%20R.\%20

Noordermeer.pdf. Accessed on: 19 Apr. 2020.

[3] Ahlström, C., Andersson, A. \& Blomgren, N., Optimus Pråm - Semi-submersible wind farm installation vessel for Blekinge Offshore, 2014.

https://publications.lib.chalmers.se/publication/208702. Accessed on: 19 Apr. 2020.

[4] Gintautas, T., Dalsgaard Sørensen, J. \& Ringdalen Vatne, S., Towards a risk-based decision support for offshore wind turbine installation and operation and maintenance. Energy Procedia, 94, pp. 207-217, 2016.

[5] Seyr, H. \& Muskulus, M., Safety indicators for the marine operations in the installation and operating phase of an offshore wind farm. Energy Procedia, 94, pp. 72-81, 2016.

[6] Paterson, J., D’Amico, F., Thies, P.R., Kurt, R.E. \& Harrison, G., Offshore wind installation vessels - A comparative assessment for UK offshore rounds 1 and 2. Ocean Engineering, 148, pp. 637-647, 2018.

[7] Gudmestad, O.T., Grønli, J. \& Straume, H., Marine operations for installation, intervention and decommissioning of offshore windmills. The Royal Institution of Naval Architects conference Marine \& Offshore Renewable Energy, London, UK, pp. 175-184, 2010.

[8] Lloyds Register, Guidance Notes for Wind Turbine Installation Vessels, 2014. London. www.lr.org/en/guidance-notes-for-wind-turbine-installation-vessels/. Accessed on: 19 Apr. 2020.

[9] DNV, Det Norske Veritas, Recommended practice, dnv-rp-h103, Modelling and analysis of marine operations, Oslo, 2011. https://rules.dnvgl.com/docs/pdf/DNV/ codes/docs/2011-04/RP-H103.pdf. Accessed on: 19 Apr. 2020.

[10] NorWind, Alpha Ventus Jacket Installations. www.sintef.no/project/Nowitech/ Wind_presentations/Jorde,\%20J.,\%20NorWind.pdf. Accessed on: 19 Apr. 2020.

[11] Jan De Nul Group, www.jandenul.com/en/wind-turbine-installation-vessel. Accessed on: 19 Apr. 2020.

[12] Van Oord. Offshore wind installation. www.vanoord.com/activities/offshore-windequipment. Accessed on: 19 Apr. 2020.

[13] Sarkar, A. \& Gudmestad, O.T., Study on a new method for installing a monopile and a fully integrated offshore wind turbine structure. Marine Structures, 33, pp. 160-187, 2013.

[14] Anstock, F., Schütt, M. \& Schorbac, V., A new approach for comparability of twoand three-bladed $20 \mathrm{MW}$ offshore wind turbines. 16th Deep Sea Offshore Wind R\&D conference, 16-18 January 2019, Trondheim, Norway, 2019.

[15] Haugvaldstad, J. \& Gudmestad, O.T., Testing of a new transport and installation method for wind turbines. IOP Conference Series: Materials Science and Engineering, 700, 2019.

[16] Skaare, B., Nielsen, F.G., Hanson, T.D., Yttervik, R., Havmøller, O. \& Rekdal, A., Analysis of measurements and simulations from the Hywind Demo floating wind turbine. Wind Energy, 18(6), pp. 1105-1122, 2015.

[17] Rodddier, D., Cermelli, C., Aubault, A. \& Peiffer, A., Summary and conclusions of the full life-cycle of the wind float FOWT prototype project. Conference on Offshore Mechanics and Arctic Engineering, Trondheim, Norway, 2017.

[18] DNVGL RPA203, Technology qualification, Recommended Practice, Høvik, Oslo, Norway, 2017. 